\title{
Urban Japanese Encephalitis: Time for a Reality Check
}

\author{
Sajal Bhattacharya', Shakya Sinha ${ }^{2}$, Chandrima Bose ${ }^{3}$, Pallab Chatterjee ${ }^{4}$, Rina Tilak $^{5}$ \\ ${ }^{1,2,3,4}$ Department of Zoology, Asutosh College (University of Calcutta), Kolkata, West Bengal, India. \\ ${ }^{5}$ Department of Community Medicine, Armed Forces Medical College, Pune, Maharashtra, India. \\ DOI: https://doi.org/10.24321/0019.5138.202112
}

\section{I $\quad \mathbf{N} \quad \mathbf{F} \quad \mathbf{O}$}

\author{
Corresponding Author: \\ Rina Tilak, Department of Community \\ Medicine, Armed Forces Medical College, Pune, \\ Maharashtra, India. \\ E-mail Id: \\ rinatilak@hotmail.com \\ Orcid Id: \\ https://orcid.org/0000-0003-3781-0210 \\ How to cite this article: \\ Bhattacharya S, Sinha S, Bose C, Chatterjee P, \\ Tilak R. Urban Japanese Encephalitis: Time for a \\ Reality Check. J Commun Dis 2021; 53(1): 72-77. \\ Date of Submission: 2021-02-01 \\ Date of Acceptance: 2021-03-23
}

\section{$\begin{array}{llllllll}\mathbf{A} & \mathbf{B} & \mathbf{S} & \mathbf{T} & \mathbf{R} & \mathbf{A} & \mathbf{C} & \mathbf{T}\end{array}$}

\begin{abstract}
Expansion of JEV from its historical rural origin in the Oriental Realm has been evident. Apprehensions were raised by several investigators that the occurrence of Japanese Encephalitis (JE) in the urban areas is a possibility. Creating wetlands, rice farms, and piggeries close to the rural-urban periphery to support the increasing urban population facilitates the migration of mosquitoes, ardeid birds, and pigs in these areas. The presence of vectors (Culex vishnui complex), reservoirs (the ardeid birds), and the amplifying hosts (pigs) together in these urban and peri-urban areas creates highly conducive situations for the JE transmission thus, creating an urban ecotype for JE. Apart from the primary vectors, JEV has been isolated from several species of mosquitoes belonging to different genera. JE antibodies have also been detected in several birds and mammals other than the known reservoirs and amplifying hosts. Such mosquitoes, birds, and mammals might be acting as complementary or maintenance vectors and reservoirs, respectively, which likely can keep the virus circulating perennially in nature. The reported occurrence of JE in urban areas from different geographical locations is decidedly indicative of the reality of the urban JE. It is thus pertinent that an inclusive approach encompassing sustained epidemiological surveillance and monitoring be adopted to formulate season-wise and area-wise strategies to contain JE both in rural and urban areas.
\end{abstract}

Keywords: Japanese Encephalitis, Virus, Vector, Reservoir, Urban Areas

\section{Introduction}

Japanese Encephalitis (JE) is a vector-borne viral zoonosis caused by the Japanese Encephalitis Virus (JEV) belonging to the family Flaviviridae. ${ }^{1}$ It is estimated that, around the world, nearly 68000 clinical JE cases occur, with about 13000 to 20000 deaths every year. ${ }^{2}$ The transmission cycle of JEV involves ardeid birds, Culex mosquitoes, pigs functioning as principal reservoirs, primary vectors, and amplification hosts respectively that keep the virus circulating in nature. ${ }^{3}$ The risk of JE is associated with rural residents living close to the rice fields and pig-rearing places. ${ }^{4}$ The rice fields in rural areas serve as breeding and larval developmental sites for the vectors of JE such as Culex tritaeniorhynchus, and eventually contribute to the disease ecology. ${ }^{5}$ Rapid urbanization to sustain the swelling urban population, changes in land-use patterns for urban agriculture, urban housing, industries, pasture, and the establishment of urban 
water bodies coupled with a continuous 'urban pull' or 'rural push' has impacted the epidemiology of JE. ${ }^{6}$ In such changing environmental situations, apprehensions have been raised that JE in urban areas might be a "possibility" expanding its reach from its traditional rural origin. ${ }^{6}$ In this context, this review is an attempt to assess and analyze the ground reality of the prevalence of urban JE ecotype, if any.

\section{Methodology}

Research studies were drawn from literature searches targeted peer-reviewed journal articles to conduct an exploratory review. The databases were used for data search during the study are PubMed, Google Scholar, and Wiley Online Library. These databases represent a range of disciplines allied to Japanese Encephalitis, Urbanization, Zoonoses, and Vector-borne diseases. The findings and observations regarding the focused topics in this review are listed in the references section accordingly.

\section{Urban JE Scenario}

There have been reports of JE case incidences in urban areas of different parts of the world by several investigators. In major cities like Kolkata (India), Delhi (India), Rourkela (India) and Dhaka (Bangladesh) (Table 1), JE cases have been reported in different periods, although they were sporadic. In urban areas of Delhi, all the patients of JE had no history of rural travel, which strongly indicates a possible local JEV transmission cycle. ${ }^{4}$ Presence of JE vectors $-C x$. tritaeniorhynchus and $C x$. vishnui with the reservoir hosts of JEV in this area further lends support to this assumption. ${ }^{4}$ Vajpayee $A$ et al. have reported JE cases in Rourkela city (Orissa) and the presence of pigs in these JE-affected areas. ${ }^{7}$ Later a study by Dash AP et al. from the urban area of Rourkela reported the presence of the JE vector, the Culex vishnui subgroup, along with JE cases. ${ }^{8}$ Sporadic case incidences of JE from Kolkata have also been reported by several investigators. ${ }^{9,10}$ Bhattacharya $S$, Santra SC have reported the presence of $C_{x}$. vishnui and $C x$. quinquefasciatus, the vectors of JE in India in the urban periphery of Kolkata. ${ }^{11}$ The peri-urban regions of Kolkata have a sizable population of pigs - the reservoir and amplifying host of JEV. Ardeid birds are also present near the water-bodies of Kolkata. ${ }^{12} \mathrm{JE}$ vectors, reservoir hosts, and amplifying hosts (pigs) were also reported from the urban and urban periphery of many cities globally viz. Shanghai (China), Lianyungang City (China), Can Tho City (Vietnam), and Phnom Penh (Cambodia) (Table 1). However, no JE cases have so far been reported from all these above mentioned four urban areas (Table 1). Nonetheless, these JE vectors and reservoir hosts in the aforesaid areas create highly conducive environments to support the JE transmission dynamics.

Table I.JEV Vectors, Reservoirs and Case incidences in Urban/ Peri-urban areas

\begin{tabular}{|c|c|c|c|c|c|}
\hline \multirow{2}{*}{$\begin{array}{l}\text { Urban/ Peri- } \\
\text { Urban Area }\end{array}$} & \multirow{2}{*}{$\begin{array}{l}\text { Vector or Suspected } \\
\text { Vectors of JEV }\end{array}$} & \multirow{2}{*}{$\begin{array}{l}\text { Reservoir Hosts of } \\
\text { JEV in Urban or Per- } \\
\text { urban Areas }\end{array}$} & \multicolumn{2}{|c|}{ JE Case Incidences } & \multirow{2}{*}{ References } \\
\hline & & & Cases & Year & \\
\hline $\begin{array}{l}\text { National Capital } \\
\text { Territory of Delhi, } \\
\text { India } \\
\end{array}$ & $\begin{array}{c}\text { Cx. vishnui, } \\
\text { Cx. pseudovishnui, } \\
\text { Cx. tritaeniorhynchus }\end{array}$ & $\begin{array}{l}\text { Pigs were present } \\
\text { and found positive } \\
\text { for JEV antibodies }\end{array}$ & 4 & 2013 & Kumari R et al. ${ }^{4}$ \\
\hline $\begin{array}{l}\text { Rourkela, Orissa, } \\
\text { India }\end{array}$ & $\begin{array}{c}\text { Cx. vishnui, } \\
\text { Cx. pseudovishnui, } \\
\text { Cx. tritaeniorhynchus }\end{array}$ & $\begin{array}{l}\text { Pigs were present in } \\
\text { JEV affected areas }\end{array}$ & 41 & 1989 & $\begin{array}{l}\text { Vajpayee } A \text { et al. }{ }^{7} \\
\text { Dash AP et al. }{ }^{8}\end{array}$ \\
\hline $\begin{array}{l}\text { Kolkata, West } \\
\text { Bengal, India }\end{array}$ & $\begin{array}{c}\text { Cx. vishnui, } \\
\text { Cx. quinquefasciatus }\end{array}$ & $\begin{array}{l}\text { The ardeid birds } \\
\text { were present in } \\
\text { Kolkata }\end{array}$ & 12 & 2007-2012 & $\begin{array}{l}\text { Taraphdar D et al. }{ }^{9} \\
\text { Chakraborty D et al. }^{10} \\
\text { Chakraborty DC, } \\
\text { Majumdar } \mathrm{S}^{11} \\
\text { Bhattacharya S, } \\
\text { Santra SC } \text { SC }^{12}\end{array}$ \\
\hline $\begin{array}{l}\text { Dhaka city, } \\
\text { Bangladesh }\end{array}$ & $\begin{array}{c}\text { Cx. vishnui, } \\
\text { Cx. gelidus, } \\
\text { Cx. tritaeniorhynchus }\end{array}$ & Not reported & 3 & 2003 & $\begin{array}{l}\text { Khan RH et al. }{ }^{13} \\
\text { Hossain MJ et al. }{ }^{14}\end{array}$ \\
\hline Shanghai, China & $\begin{array}{l}\text { Cx. tritaeniorhynchus, } \\
\text { Cx. pipiens }\end{array}$ & Not Reported & $\begin{array}{c}\text { Not } \\
\text { Reported }\end{array}$ & & Fang Y et al. ${ }^{15}$ \\
\hline $\begin{array}{l}\text { Can Tho City, } \\
\text { Vietnam }\end{array}$ & $\begin{array}{c}\text { Cx. vishnui, } \\
\text { Cx. gelidus, } \\
\text { Cx. tritaeniorhynchus }\end{array}$ & $\begin{array}{l}\text { Pig farming in the } \\
\text { urban periphery }\end{array}$ & $\begin{array}{c}\text { Not } \\
\text { Reported }\end{array}$ & & Lindahl J et al. ${ }^{16}$ \\
\hline
\end{tabular}




\begin{tabular}{|c|c|c|c|c|c|}
\hline $\begin{array}{c}\text { Phnom Penh, } \\
\text { Cambodia }\end{array}$ & $\begin{array}{c}\text { Cx. vishnui, } \\
\text { Cx. gelidus, } \\
\text { Cx. tritaeniorhynchus }\end{array}$ & $\begin{array}{c}\text { Sentinel pig } \\
\text { population in peri- } \\
\text { urban areas }\end{array}$ & $\begin{array}{c}\text { Not } \\
\text { Reported }\end{array}$ & Di Francesco J et al. ${ }^{17}$ \\
\hline $\begin{array}{c}\text { Lianyungang City, } \\
\text { Jiangsu province, } \\
\text { China }\end{array}$ & Cx. tritaeniorhynchus & $\begin{array}{c}\text { JEV isolated from the } \\
\text { pigs }\end{array}$ & $\begin{array}{c}\text { Not } \\
\text { Reported }\end{array}$ & ${\text { Chu H et al. }{ }^{18}}$ \\
\hline
\end{tabular}

\section{Vectors and suspected vectors of JE}

JEV primarily gets transmitted by the mosquitoes belonging to Culex vishnui subgroup constituted by $C x$. tritaeniorhynchus, $C x$. vishnui and $C x$. pseudovishnui. ${ }^{4,19,20}$ In addition to the confirmed primary vectors of JE, the Culex vishnui subgroup, several other mosquitoes belonging to different genera were assumed to be contributing to the epidemiology of JEV as complementary or secondary vectors following the isolation of the virus from them. $C x$. annulirostris, $C x$. annulus, Cx. fuscocephala, $C x$. gelidus, and $C x$. sitiens are the most cited competent vectors apart from the $C x$. vishnui subgroup within the Culex genus. ${ }^{21}$ Scientists have speculated that An. subpictus could contribute to the epidemiology of JE owing to their presence in high numbers during JE epidemics in certain parts of India. ${ }^{22,23}$ Isolation of JEV from other commonly encountered mosquito species viz. An. peditaeniatus, An. barbirostris and An. pallidus has been reported. ${ }^{23,24}$ The vectorial competence of $A e$. Albopictus, Ae japonicas, and Ae. Detritus mosquitoes also were demonstrated by investigators. ${ }^{25-27}$ Among these mosquitoes, Ae. albopictus as a contributor to the transmission dynamics of JEV could be significant due to its wide home-range and anthropo-zoophilic feeding behavior. ${ }^{19} \mathrm{JEV}$ was isolated from mosquitoes belonging to genera Mansonia and Armigeres also. ${ }^{28}$ However, the role of these mosquitoes as complementary vectors for JEV, if any, has not been established as yet. Further studies are required to determine their possible impact on the epidemiology of the disease.

\section{Vertebrate Reservoirs and Amplifier Hosts of JE}

The transmission dynamics of JEV primarily involve birds, mosquitoes and swine. ${ }^{3}$ Several paddy field birds belonging to the family Ardeidae viz. the egrets, herons, cranes are the principal reservoir hosts of JEV. ${ }^{29}$ Domestic birds such as chickens, ducks, and pigeons were apprehended as possible reservoir hosts for JEV as they had attained reasonably good level of blood viremia during experimental investigation. ${ }^{22}$ Besides that, pigs are primarily considered the principal amplifying host of JE in the endemic areas. ${ }^{30,4}$ The intraspecific transmission of JEV via nasal secretions of pigs without mosquito vectors has also been reported and could be a significant component in its disease epidemiology. ${ }^{31}$ Isolation of JEV from bats has been evident, but their role as the reservoir for the virus needs further investigation. ${ }^{32}$
The isolation of JEV from some poikilothermic reptiles like snakes and freshwater turtles has also been reported. ${ }^{33,34}$

\section{Impact of Urbanization, Land-use Change, and Deforestation on the Ecology of JE}

Rapid urbanization is a reason behind the changing epidemiology of several vector-borne zoonoses. ${ }^{16}$ To sustain the growing demands of the urban population, land-use changes in the form of the creation of new agricultural lands, water bodies could significantly moderate the disease dynamics of JEV. ${ }^{16}$ The establishment of water bodies provides the ideal breeding ground for mosquitoes such as $C x$. tritaeniorhynchus, which are traditionally prevalent in rural rice cultivating areas and act as primary vectors for JE. ${ }^{5}$ The destruction of habitats of the avian reservoir hosts such as ardeid birds forces them to find new habitats for foraging and breeding in the modified lands such as urban or peri-urban water bodies, which brings them in close proximity to humans. ${ }^{35}$ The livestock rearing in peri-urban areas also tends to modify the host range of the JEV. ${ }^{36}$ Domestic pig rearing is a risk factor for JEV transmission to humans, as infected pigs are the main amplifying hosts for JEV. ${ }^{37}$ Lindahl J et al. provided evidence of increased density of $C X$. vishnui complex mosquitoes in urban areas where pig-rearing was being undertaken. ${ }^{16}$ It emphasizes the role of pig farming as a contributor in likely urban JE transmission.

\section{Discussion}

Historically, JE has been endemic in the rural regions of the Oriental realm as the cause of mosquito-borne viral encephalitis. Evidence of the introduction of JEV into Northern Australia from a source in Papua New Guinea confirms its expansion into newer geographical areas. ${ }^{38}$ Climate change and global warming have been delineated as supporting factors for the expansion of vector-borne zoonoses by several authors. ${ }^{39,40}$ In warmer temperatures, female mosquitoes tend to have blood meals more frequently. ${ }^{40}$ Moreover, the vector density also increases in a warmer climate with increased breeding and the ability to invade higher altitudes for vector mosquitoes. ${ }^{40}$ Rapid urbanization, deforestation, globalization, industrialization, construction and irrigation has changed the environmental conditions in rural and urban habitats of the vectors, reservoirs and hosts for several diseases. ${ }^{41}$ These changes could also act as a driver 
for the spread of JEV in newer areas. Expansion of cities to accommodate the growing urban population has led to the urban boundaries coming closer to the rural stretches. Eventually, to sustain the swelling urban population, urban forestry and urban water-bodies are being created, giving rise to novel urban ecosystems. As a result, the prevalence of wading water birds like storks, herons, egrets inhabiting these urban water-bodies are rising, thereby introducing possible new reservoirs of JEV in urban areas. ${ }^{12,42}$ These wetlands additionally provide breeding grounds for mosquitoes to sustain themselves in urban conditions. ${ }^{19}$ The isolation of JEV from certain species of genus Anopheles, Mansonia, Aedes, and Culex mosquitoes, apart from their primary vectors, the Culex vishnui subgroup, has been well demonstrated. However, virus isolation from these mosquitoes is not enough to confirm their vectorial status and needs further investigations to prove their decisive role in JE transmission. These mosquitoes could play a significant role as possible complementary or maintenance vectors for JEV and with the passage of time, may attain the status of vectors. ${ }^{1}$ It is well-established that the diverse feeding habits of principal and complementary vectors can facilitate the virus to circulate perennially in nature. ${ }^{43}$ The growing food demand of the expanding urban communities met through livestock (cattle farming) rearing along with rice farming and the creation of piggeries in the peri-urban areas has led to an abundance of pigs -the amplifier host of JEV thereby, enhancing the risk of JE transmission in these areas. ${ }^{6}$ The possibility of enzootic cycles of JEV to exist in such mosquitogenic and virogenic environments is highly probable. Involvement of the young, non-immune pigs, nestling birds, and other mammalian populations in the transmission dynamics of JEV could facilitate and transform the enzootic cycle into the epizootic cycle. ${ }^{44,45,50} \mathrm{It}$ is highly likely that during the increased viral load in these animals, JEV may tangentially spillover to humans. ${ }^{1}$ Bhattacharya $S$ et al. showed that the JEV antibodies were prevalent in wild birds and sentinel chicks perennially, and when the average level of virus circulation increases human infection happens periodically that is, at the peak of the epizootic cycle. ${ }^{44}$ Antibodies against JEV have also been detected from several animals apart from the known reservoirs, the ardeid birds and pigs, which have added a new dimension in the epidemiology of JE. Among these animals, ducks, chicken, pigeons, bats are commonly present in urban and peri-urban areas. However, the detection of JE antibody is not enough to attain the status of the reservoir for JE, but with the passage of time, these animals could be epidemiologically important and could play the role of complementary or secondary reservoirs/hosts by helping the virus to sustain during the enzootic cycle in urban environments. ${ }^{1}$ Further experimental studies are required to understand the contribution of these complementary hosts in the transmission dynamics of JEV. Moreover, mosquitoes prevalent in rural-urban eco-epidemiological zones, such as Culex quinquefasciatus, could also act as an ecological bridge vector between urban, peri-urban, and rural areas as well as a bridge vector between human, pigs, and birds owing to their distribution and diverse feeding habits. ${ }^{46,47}$ Isolation of JEV from Culex quinquefasciatus has been documented by investigators. ${ }^{48}$

Lindahl J had apprehended the "possibility" of an urban JE. ${ }^{6}$ The case incidences of JE in cities such as Delhi (India) and Katmandu (Nepal) without any rural travel history are significant and hint towards the probable urban indigenous transmission cycle of JE. ${ }^{4,6,49}$ This scenario reinforces the existence of an urban ecotype for JEV, thus, making urban JE seems reality now. However, the magnitude of the urban JE appears to be minuscule at present. It is thus extremely important and imperative necessity that in all urban areas where JE disease ecology is prevalent with the recorded presence of vectors, reservoir hosts, and susceptible populations, thorough investigations need to be prioritized and strategies formulated to avert the urban JE outbreaks, if any.

\section{Conclusion}

The transmission dynamics of vector-borne viral zoonosis are complex, with several components. The changing disease ecology of vector-borne diseases due to several anthropogenic and environmental factors facilitates their spread to newer areas. Urbanization and subsequent land-use changes create favorable situations for the transmission and maintenance of JEV in the urban and suburban periphery. The prevalence of JE vectors, reservoir hosts, with JE incidences in certain urban areas indicates the reality of the existence of urban JE ecotype. Sustained surveillance and thorough monitoring of vector, virus, and vertebrate reservoir hosts in urban areas are required to prevent any possible future outbreaks of urban JE.

\section{References}

1. Bhattacharya S, Basu P. Japanese Encephalitis Virus (JEV) infection in different vertebrates and its epidemiological significance: A review. Int J of Fauna and Biol Studies 2014; 1(6): 32-37.

2. WHO. Japanese Encephalitis Reported Cases, World Health Organization. 2019 Available from: https:// www.who.int/news-room/fact-sheets/detail/japaneseencephalitis.

3. Weaver SC, Barrett AD. Transmission cycles, host range, evolution and emergence of arboviral disease. Nat Rev Microbiol 2004; 2(10): 789-801.

4. Kumari R, Kumar K, Rawat A et al. First indigenous transmission of Japanese Encephalitis in urban areas of National Capital Territory of Delhi, India. Trop Med 
Int Health 2013; 18(6): 743-9.

5. Rosen L. The natural history of Japanese encephalitis virus. Annu Rev Microbiol 1986; 40: 395-414.

6. Lindahl J. Urbanization and vector-borne disease emergence - a possibility for Japanese Encephalitis virus? British J of Virology 2014; 1(1): 10-20.

7. Vajpayee A, Mukherjee MK, Chakraborty AK et al. Investigation of an outbreak of Japanese encephalitis in Rourkela City (Orissa) during 1989. J Commun Dis 1991; 23(1): 18-21.

8. Dash AP, Chhotray GP, Mahapatra N et al. Retrospective analysis of epidemiological investigation of Japanese encephalitis outbreak occurred in Rourkela, Orissa, India. Southeast Asian J Trop Med Public Health 2001; 32(1): 137-139.

9. Taraphdar D, Sarkar A, Mukhopadhyay BB et al. Increasing trend of Japanese encephalitis cases in West Bengal, India - a threat to paediatric population. Asia Pacific J of Tropical Med 2012; 2(5): 358-361.

10. Chakraborty D, Banerjee S, Maji D et al. A descriptive study of Japanese encephalitis in West Bengal, India, based on surveillance data: changing pattern observed in recent years. Sch J App Med Sci 2015; 3(1E): 320-328.

11. Bhattacharya S, Santra SC. Mosquito-borne diseases and vector diversity in Kolkata with special to Malaria. In.: Perspectives in Environmental Health: vector and water borne diseases (Eds.: Mukhopadhyay A, Dey AK.) Published by Originals, Delhi, India. 2005, pp.53-70.

12. Chakraborty DC, Majumdar S. Urban Heronries of Kolkata Metropolitan: an insight to nest stratification, resource based guilds and conservation priorities. Asian $J$ of Conservation Biol 2018; 7(2): 106-12.

13. Khan RH, Islam M, Akter T et al. Diversity of mosquitoes and their seasonal fluctuation in two wards of Dhaka city. Dhaka Univ J of Biol Sci 2014; 23(1): 17-26.

14. Hossain MJ, Gurley ES, Montgomery S et al. Hospitalbased surveillance for Japanese encephalitis at four sites in Bangladesh, 2003-2005. Am J Trop Med Hyg 2010; 82(2): 344-349.

15. Fang $Y$, Zhang $Y$, Zhou ZB et al. New strains of Japanese encephalitis virus circulating in Shanghai, China after a ten-year hiatus in local mosquito surveillance. Parasites and Vectors 2019; 12(22): 1-14.

16. Lindahl J, Chirico J, Boqvist $S$ et al. Occurrence of Japanese encephalitis virus mosquito vectors in relation to urban pig holdings. Am J Trop Med Hyg 2012; 87(6): 1076-1082.

17. Di Francesco J, Choeung R, Peng B et al. Comparison of the dynamics of Japanese encephalitis virus circulation in sentinel pigs between a rural and a peri-urban setting in Cambodia. PLoS Neg/ Trop Dis 2018; 12(8): e0006644.

18. Chu H, Wu Z, Chen $\mathrm{H}$ et al. Japanese encephalitis virus infection rate and detection of genotype i from culex tritaeniorhynchus collected from Jiangsu, China. Vector Borne Zoonotic Dis 2017; 17(7): 503-509.

19. Pearce JC, Learoyd TP, Langendorf BJ et al. Japanese encephalitis: the vectors, ecology and potential for expansion. J Travel Med 2018; 25(suppl_1): S16-26.

20. Reuben R, Tewari SC, Hiriyan J et al. Illustrated keys to species of Culex (Culex) associated with Japanese encephalitis in Southeast Asia (Diptera: Culicidae). Mosquito Systematics 1994; 26: 75-96.

21. Le Flohic G, Porphyre V, Barbazan P et al. Review of climate, landscape, and viral genetics as drivers of the Japanese encephalitis virus ecology. PLoS Negl Trop Dis 2013; 7(9): e2208.

22. Dhanda V, Banerjee K, Deshmukh PK et al. Experimental viraemia and transmission of Japanese encephalitis virus by mosquitoes in domestic ducks. Indian J Med Res 1977; 66(6): 881-888.

23. Thenmozhi V, Balaji T, Venkatasubramani K et al. Role of Anopheles subpictus Grassi in Japanese encephalitis virus transmission in Tirunelveli, South India. Indian J Med Res 2016; 144(3): 477-481.

24. Mourya DT, Ilkal MA, Mishra AC et al. Isolation of Japanese encephalitis virus from mosquitoes collected in Karnataka state, India from 1985 to 1987 . Trans $R$ Soc Trop Med Hyg 1989; 83(4): 550-552.

25. de Wispelaere $M$, Desprès $P$, Choumet V. European Aedes albopictus and Culex pipiens Are Competent Vectors for Japanese Encephalitis Virus. PLoS Negl Trop Dis 2017; 11(1): e0005294.

26. Huber K, Jansen S, Leggewie M et al. Aedes japonicus japonicus (Diptera: Culicidae) from Germany have vector competence for Japan encephalitis virus but are refractory to infection with West Nile virus. Parasitol Res 2014; 113(9): 3195-3199.

27. Mackenzie-Impoinvil L, Impoinvil DE, Galbraith SE et al. Evaluation of a temperate climate mosquito, Ochlerotatus detritus (=Aedes detritus), as a potential vector of Japanese encephalitis virus. Med Vet Entomol 2015; 29(1): 1-9.

28. Tyagi BK, Thenmozhi V, Karthigai SS. Transmission dynamics of Japanese encephalitis with emphasis on gaps in understanding and priority areas for research on Japanese encephalitis and other acute encephalitis syndrome in India. J Commun Dis 2014; 46: 24-34.

29. Filgueira L, Lannes N. Review of emerging Japanese encephalitis virus: new aspects and concepts about entry into the brain and inter-cellular spreading. Pathogens 2019; 8(3): 111.

30. Mackenzie JS, Williams DT, Smith DW. Japanese encephalitis virus: the geographic distribution, incidence and spread of a virus with a propensity to emerge in new areas. Perspectives in Med Virol 2006; 16: 201-268. 
31. Ricklin ME, García-Nicolás O, Brechbühl D et al. Vector-free transmission and persistence of Japanese encephalitis virus in pigs. Nat Commun 2016; 7: 10832.

32. Wang JL, Pan XL, Zhang HL et al. Japanese encephalitis viruses from bats in Yunnan, China. Emerg Infect Dis 2009; 15(6): 939-942.

33. Lee $H$, Min B, Lim Y. Isolation and serologic studies of Japanese encephalitis virus from snakes in Korea. J Korean Am Med Assoc 1972; 15: 69-74.

34. Shortridge KF, Oya A, Kobayashi M et al. Arbovirus infections in reptiles: studies on the presence of Japanese encephalitis virus antibody in the plasma of the turtle, Trionyx sinensis. Southeast Asian J Trop Med Public Health 1975; 6(2): 161-169.

35. Sehgal RN. Deforestation and avian infectious diseases. $J$ Exp Biol 2010; 213(6): 955-960.

36. Erlanger TE, Weiss S, Keiser J et al. Past, present, and future of Japanese encephalitis. Emerg Infect Dis 2009; 15(1): 1-7.

37. Solomon T. Control of Japanese encephalitis--within our grasp? N Engl J Med 2006; 355(9): 869-871.

38. Hanna JN, Ritchie SA, Phillips DA et al. An outbreak of Japanese encephalitis in the Torres Strait, Australia, 1995. Med J Aust 1996; 165(5): 256-260.

39. Hsu SM, Yen AM, Chen TH. The impact of climate on Japanese encephalitis. Epidemiol Infect 2008; 136(7): 980-7.

40. Sakamoto R, Tanimoto T, Takahashi K et al. Flourishing Japanese encephalitis, associated with global warming and urbanisation in Asia, demands widespread integrated vaccination programmes. Ann Glob Health 2019; 85(1): 111.

41. Caminade $\mathrm{C}$, Mclntyre KM, Jones AE. Impact of recent and future climate change on vector-borne diseases. Ann N Y Acad Sci 2019; 1436(1): 157-173.

42. Traut, AH, Hostetler ME. Urban lakes and water birds: effects of development on avian behavior. Water birds: The Int J of Waterbird Biol 2003; 26(3): 290-302.

43. Hati AK, Bhattacharya S. Biosystematics of Culex Vishnui and Culex pseudovishnui based on eco-behavioral pattern. Proc Ind Acad SCI (Anim. Sci.) 1987; 96: 629636.

44. Bhattacharya S, Chakraborty SK, Chakraborty S et al. Density of Culex vishnui and appearance of JE antibody in Sentinel chicks and wild birds in relation to Japanese encephalitis cases. Trop Geogr Med 1986; 38: 46-50.

45. Bhattacharya S. Mosquito Borne diseases in India with special reference to Malaria Vectors and their Control. $J$ of the Asiatic Society 2009; L1(2): 15-34.

46. Bhattacharya S, Chakraborty S, Mitra AK, et al. Blood meal analysis of certain species of mosquitoes of rural West Bengal. Bull Cal Sch Trop Med 1982; 30: 43-45.

47. Bhattacharya S, Basu P. The Southern House Mosquito,
Culex quinquefasciatus: profile of a smart vector. J Ent and Zoo Studies 2016; 4(2): 73-81.

48. Nitatpattana N, Apiwathnasorn C, Barbazan P et al. First isolation of Japanese encephalitis from Culex quinquefasciatus in Thailand. Southeast Asian J Trop Med Public Health 2005; 36(4): 875-878.

49. Partridge J, Ghimire P, Sedai T, et al. Endemic Japanese encephalitis in the Kathmandu valley, Nepal. Am J Trop Med Hyg 2007; 77(6): 1146-9.

50. Bhattacharya S, Hati AK. Transmission Dynamics of Japanese encephalitis in an endemic area of India. Acta Parasitologica Portuguesa 1998; 5(1): 6. 